\title{
Examining the Effects of Traders' Overconfidence on Market Behavior
}

\author{
Chia-Hsuan Yeh $^{\mathrm{a}, *}$, Chun-Yi Yang ${ }^{\mathrm{b}}$ \\ ${ }^{a}$ Department of Information Management, Yuan Ze University, Chungli, Taoyuan \\ 320, Taiwan \\ b Tinbergen Institute, Roetersstraat 31, 1018 WB Amsterdam, The Netherlands
}

\begin{abstract}
This paper provides an agent-based artificial financial market to examine the effects of traders' overconfidence. Traders' overconfidence is presented in the way that they usually underestimate their volatility. We find that overconfidence results in higher volatility, price distortion, and trading volume. The phenomena of fat-tail of return distribution and volatility clustering are more significant when traders are overconfident.
\end{abstract}

Key words: Rationality, Overconfidence, Artificial Stock Market, Agent-Based Modeling, Genetic Programming

JEL classification: D83, D84, G11, G12

\section{Introduction}

It is well-known that modern financial economic theory heavily relies on the assumption that the representative agent in the market behaves rationally and has rational expectations. Under this assumption, it is shown that asset prices fully reflect all available information and always reflect their intrinsic value. In this situation, future price movements cannot be predicted on the basis of past information. Any financial regulation imposed on the market should generate no substantial effects but result in delayed revelation of the information. Milton Friedman is one of the strongest advocates for supporting rational expectations approach. In Friedman (1953, p. 175): "People who argue that speculation is generally destabilizing seldom realize that this is largely equivalent to saying that speculators lose money, since speculation can be destabilizing in general only if speculators on the average sell when the currency is low in price and buy when it is high."

* Corresponding author. Tel: +886 34638800 ext. 2616, Fax: +886 34352077

Email addresses: imcyeh@saturn.yzu.edu.tw (Chia-Hsuan Yeh), cyang@tinbergen.nl (Chun-Yi Yang).

URL: http://comp-int.mis.yzu.edu.tw/faculty/yeh/ (Chia-Hsuan Yeh). 
Examining the efficiency of real financial markets has been an interesting topic in the past three decades. Many studies have questioned the validity of the Efficient Market Hypothesis $(\mathrm{EMH})$ in real financial markets and provide the theoretical foundations or empirical evidences to show the existence of market inefficiency. De Long et al. (1991) points out that noise traders may survive in the long run and exert their impact on price dynamics. Kogan et al. (2006) further indicate that irrational traders can persistently maintain a large impact even though their relative wealth becomes quite small. In Lo and MacKinlay (1988), Campbell and Shiller (1988), Brock et al. (1992), and Neely et al. (1997), they all find the evidence of predictability and profitability in financial markets. In addition, the increasing empirical evidences have indicated that traditional asset pricing models such as the capital asset pricing model (CAPM), arbitrage pricing theory (APT), and intertemporal capital asset pricing model are unable to provide explanations regarding the stylized facts. Financial markets usually experience several anomalies such as event-based return predictability, shortterm momentum, long-term reversal, high volatility of asset prices relative to fundamentals where bubbles and crashes never cease. These phenomena cannot be purely explained by the changes in fundamentals. Given these findings, it is reasonable to reexamine the theory of finance based on imperfect rationality.

Actually, studying economics and finance from the perspective of imperfective rationality has both theoretical and empirical foundations. The reason for economists holding the assumption of rational expectations is that the economic systems without this restriction may produce numerous outcomes so that prediction is impossible. Simon (1957) argued that agents possess imperfect information or knowledge regarding the environment and they also have limited ability in processing information. Therefore, bounded rationality is a more reasonable and more appropriate description regarding agents' behavior than perfect rationality. The empirical evidence from cognitive psychology also supports that agents do not behave rationally. As mentioned in Hirshleifer (2001), traders in financial markets exhibit several phenomena deviated from perfect rationality such as overreaction toward salient news, underreaction toward less salient news, anchoring, loss aversion, mental accounting, herding, and the overconfidence.

In the past two decades, research studies devoted in financial economics have considered the models deviated from full rationality. One branch focuses on the effects of noise traders, e.g. De Long et al. (1989, 1990a, 1990b, 1991) and Shleifer and Summers (1990). Their finding have demonstrated that the presence of noise traders can generate substantial effects which are quite different from those observed in the market populated with rational traders alone. The other branch focuses on the consequences resulting from traders' psychological biases. This line of research has been an important issue in the field of behavioral finance.

DeBondt and Thaler (1995) states that perhaps the most robust finding in the psychology of judgment is that people are overconfident. In Tversky and Kahneman (1974), they points out that traders' overconfidence may be due to an "anchoring and adjustment" process. The anchor has a major influence so that the adjustment is usually insufficiently. Therefore, traders have tight subjective probability distributions. This phenomenon is also evidenced by empirical literature on judgment under uncertainty. Benos (1998) then believes that selection and survivorship biases may also be sources of overconfidence and successful traders usually 
overestimate their own contribution to their success. Such a reasoning is supported by the attribution theory, e.g. Bem (1965), in which it describes that individuals usually attribute outcomes that support the validity of their decisions to high ability, and outcomes that are inconsistent with the decisions to external noise.

However, theoretical results heavily rely on specific assumptions regarding the characteristics of traders as well as the market environments, and the information structures. Since many factors are involved, and traders' behavior may generate externalities on others, it would have a more clear and concrete picture about the effects of traders' psychological biases if a heterogeneous-agent framework is employed. In fact, Hirshleifer (2001) mentioned that,

The great missing chapter in asset-pricing theory, I believe, is a model of the social process by which people form and transmit ideas about markets and securities. (p. 1577)

Under a well-controlled heterogeneous-agent environment where traders' psychological factors are considered, we are able to examine the market phenomena from the perspective of micro-foundation. However, such a framework would be too complicated so that analytical results are difficult to be derived. Therefore, a simulated framework composed of many heterogeneous and bounded-rational traders whose learning behavior is appropriately represented would be a better architecture. In this paper, we provide an agent-based artificial financial market to examine the effects of traders' overconfidence on several stylized facts such as volatility clustering, and fat tails for the return series.

The remainder of this paper is organized as follows. The basic framework of the model which includes the market environment, the traders' learning behavior, and the mechanism of price determination are described in Section 2. Section 3 presents the simulation design, and the results are summarized in Section 4. Section 5 concludes.

\section{The model}

\subsection{Market structure}

The basic framework of the artificial stock market considered in this paper is the standard asset pricing model with many heterogeneous traders. All traders are characterized by bounded rationality in which they are equipped with adaptive learning behavior represented by the genetic programming (GP) algorithm. In the framework of GP, traders are freely allowed to form various types of forecasting functions which may be fundamental-like or technical-like rules in different time periods

Our framework is very similar to that used in Yeh (2008). However, to calibrate the model being able to fit different time horizons of real financial markets, we follow the design proposed in $\mathrm{He}$ and $\mathrm{Li}$ (2007).

Consider an economy with two assets. One is the risk free asset called money which is perfectly elastically supplied. Its gross return is $R=1+r / K$, where $r$ is a constant interest rate per annum and $K$ represents the trading frequency measured in one year. For example, $K=1$, 12,52 , and 250 stand for the trading periods of year, month, week, and day, respectively. The other asset is a stock with a stochastic dividend process $\left(D_{t}\right)$ not known to traders. The 
trader $i$ 's wealth at $t+1, W_{i, t+1}$, is given by

$$
W_{i, t+1}=R W_{i, t}+\left(P_{t+1}+D_{t+1}-R P_{t}\right) h_{i, t}
$$

where $P_{t}$ is the price (ex dividend) per share of the stock and $h_{i, t}$ denotes the shares of the stock held by trader $i$ at time $t$. Let $R_{t+1}$ be the excess return at $t+1$, i.e. $P_{t+1}+D_{t+1}-R P_{t}$, and $E_{i, t}(\cdot)$ and $V_{i, t}(\cdot)$ are the forecasts of trader $i$ about conditional expectation and variance at $t+1$ given his information up to $t$ (the information set $I_{i, t}$ ), respectively. Then we have

$$
\begin{aligned}
& E_{i, t}\left(W_{t+1}\right)=R W_{i, t}+E_{i, t}\left(P_{t+1}+D_{t+1}-R P_{t}\right) h_{i, t}=R W_{i, t}+E_{i, t}\left(R_{t+1}\right) h_{i, t}, \\
& V_{i, t}\left(W_{t+1}\right)=h_{i, t}^{2} V_{i, t}\left(P_{t+1}+D_{t+1}-R P_{t}\right)=h_{i, t}^{2} V_{i, t}\left(R_{t+1}\right)=h_{i, t}^{2} \sigma_{i, t}^{2},
\end{aligned}
$$

where $\sigma_{i, t}^{2}$ is the conditional variance of $(P+D)$ given $I_{i, t}$. Assume that all traders follow the same constant absolute risk aversion (CARA) utility function, i.e. $U\left(W_{i, t}\right)=-\exp \left(-\lambda W_{i, t}\right)$, where $\lambda$ is the degree of absolute risk aversion. At the beginning of each period, each trader myopically maximizes the one-period expected utility function subject to Eq. (1). Assuming that traders' forecasts regarding the sum of the next period's price and dividend follow the Gaussian distributions, trader $i$ 's optimal share of stock holding, $h_{i, t}^{*}$, solves

$$
\max _{h}\left\{E_{i, t}\left(W_{t+1}\right)-\frac{\lambda}{2} V_{i, t}\left(W_{t+1}\right)\right\}
$$

that is,

$$
h_{i, t}^{*}=\frac{E_{i, t}\left(R_{t+1}\right)}{\lambda V_{i, t}\left(R_{t+1}\right)} \text {. }
$$

If it is supposed that the current stock holding for trader $i$ is at the optimal level, i.e. $h_{i, t}^{*}=h_{i, t}$, then the trader's reservation price, $P_{i}^{\Re}$, can be derived.

$$
P_{i}^{\Re}=\frac{E_{i, t}\left(P_{t+1}+D_{t+1}\right)-\lambda h_{i, t} \sigma_{i, t}^{2}}{R} .
$$

When traders possess homogeneous rational expectations, the fundamental price $P_{f}$ is given by

$$
P_{f, t}=\sum_{i=1}^{\infty} \frac{E_{t}\left[D_{t+i}\right]}{R^{i}}
$$

\subsection{Learning of traders}

According to Eq. (6), it is shown that traders' reservation prices rely on their conditional expectations and variances regarding $P+D$. We adopt the functional form for $E_{i, t}(\cdot)$ :

$$
E_{i, t}\left(P_{t+1}+D_{t+1}\right)= \begin{cases}\left(P_{t}+D_{t}\right)\left[1+\theta_{0} \tanh \left(\frac{\ln \left(1+f_{i, t}\right)}{\omega}\right)\right] & \text { if } f_{i, t} \geq 0.0 \\ \left(P_{t}+D_{t}\right)\left[1-\theta_{0} \tanh \left(\frac{\ln \left(\left|-1+f_{i, t}\right|\right)}{\omega}\right)\right] & \text { if } \quad f_{i, t}<0.0\end{cases}
$$


where $f_{i, t}$ is evolved using GP based on $I_{i, t}{ }^{1}$

The modeling of traders' conditional variances also plays an important role. Here we consider the following form of conditional variance:

$$
\sigma_{i, t}^{2}=\left(1-\theta_{1}-\theta_{2}\right) \sigma_{i, t-1}^{2}+\theta_{1}\left(P_{t}+D_{t}-u_{t-1}\right)^{2}+\theta_{2}\left[\left(P_{t}+D_{t}\right)-E_{i, t-1}\left(P_{t}+D_{t}\right)\right]^{2},
$$

where

$$
u_{t}=\left(1-\theta_{1}\right) u_{t-1}+\theta_{1}\left(P_{t}+D_{t}\right)
$$

Traders update their own estimated conditional variance of the active rule at the end of each period.

Each trader's overconfidence level is modeled as the degree of underestimation about the conditional variance. Therefore, the conditional variance shown in Eq. (9), $\sigma_{i, t}^{2}$, is replaced by $\Omega_{i, t}^{2}$ :

$$
\Omega_{i, t}^{2}=\gamma(t) \sigma_{i, t}^{2}
$$

where

$$
\gamma(t)= \begin{cases}\gamma_{1}, & \text { if profit }>0 \\ \gamma_{2}, & \text { if profit }<0 \\ 1, & \text { if profit }=0\end{cases}
$$

The values of $\gamma_{1}\left(\gamma_{2}\right)$ should be smaller (greater) than 1 , and $\left|1-\gamma_{1}\right|>\left|\gamma_{2}-1\right|$. The last condition is used to model the behavior of biased self-attribution.

Each trader possesses several models, say $N_{I}$, which are represented by GP. The performance of each forecasting model is indicated by the value of strength which is defined by

$$
s_{i, j, t}=-\Omega_{i, j, t}^{2}
$$

where $\mathrm{s}_{i, j, t}$ is the strength of the $j$ th model for trader $i$ in period $t$. Traders learn to make better forecasts through an adaptation process that abandons the model with poorest performance and generates a new one by means of an evolutionary process devised in GP. The evolutionary process takes place every $N_{E C}$ periods (evolution cycle) for each trader asynchronously. Traders' learning works as follows. At the beginning of each evolution cycle, each trader randomly chooses $N_{T}$ out of $N_{I}$ models. The one with the highest strength value is

1 Regarding the formation of a function by means of GP as well as the implementation of GP, the reader should refer to Yeh (2007). 
selected as the model he uses in these periods of this evolution cycle. At the end of each evolution cycle, the model with the lowest strength is replaced by the model which is created by means of crossover, mutation, or immigration.

A simplified double auction (DA) is employed as the trading mechanism. Each period is decomposed into $N_{R}$ rounds. At the beginning of each round, a new random permutation of all traders is performed to determine their order of bid and ask. Each trader, based on his own reservation price and current best bid or ask, he makes a decision of his offer. If a bid (ask) exists, any subsequent bid (ask) must be higher (lower) than the current one. For the sake of simplicity, only a fixed amount of stock $(\Delta h)$ is traded in each transaction. The last transaction price (closing price) in each period is recorded as the market price for this period. ${ }^{2}$

\section{Simulation design}

\subsection{Stylized facts}

Before conducting our simulations, we first present several stylized facts observed in real financial markets. The basic statistical properties of the Dow Jones Industrial Average Index (DJIA), Nasdaq Composite Index, and S\&P 500 are summarized in Table 1.

The third and fourth columns show the minimum and maximum returns in percentage, respectively. The market volatility in terms of the average of absolute returns is described in the fifth column. The sixth column is the kurtosis $K$. It is evident that the kurtosis of all markets are greater than 3 , which is an indication of fat tails. The tail index $\alpha$ which is a more reliable estimator of fat-tail is presented in seventh column. The smaller the $\alpha$ value is, the fatter the tail is. The $\alpha$ value is obtained based on 5 percent of the largest observations. Hurst exponent is employed to identify whether a time series follows a random walk or it possesses underlying trends. The value of Hurst exponent $(H)$ is between 0 and 1. A random series has the value of 0.5 , while $0.5<H<1(0<H<0.5)$ implies a time series with persistence (anti-persistence). The Hurst exponents of raw returns and absolute returns are shown in the last two columns, respectively. In Table 1, the raw return series of all markets are close to random series. By contrast, the absolute return series exhibit strong sign of volatility clustering. These phenomena can be also evidenced in Fig. 1 which displays basic properties of Nasdaq. Fig. 1 is the time series plot during 1972-2007. The distribution of the returns is presented in the third panel of Fig. 1 in which the black line is the normal distribution with the same variance. It is clear that the return distribution of Nasdaq possesses higher probabilities around the mean and the tails than those of the normal distribution. In addition, at the $5 \%$ significance level, the insignificant autocorrelation of raw returns for most lag periods and the significant autocorrelation of absolute returns are exhibited in the last two panels.

\subsection{Model calibration}

We calibrate the model to mimic the stylized facts of the daily data in financial markets observed in Table 1 and Fig. 1. The model parameters are shown in Table 2. Adopting the same setup of $\mathrm{He}$ and $\mathrm{Li}$ (2007), the annual interest rate $r$ is set as $5 \%$, i.e., the daily interest rate, $r_{d}=0.05 / 250=0.02 \%$. The daily dividend process is assumed to follow normal

$\overline{2}$ For a more detailed implementation, please refer to Yeh (2008). 
Table 1

Stylized facts of financial markets

\begin{tabular}{lcrrrrrrr}
\hline Series & Period & $r_{\min }$ & $r_{\max }$ & $|r|$ & $K$ & $\alpha$ & $H_{r}$ & $H_{|r|}$ \\
\hline DJIA & $1972-2007$ & -29.22 & 9.21 & 0.72 & 77.03 & 4.25 & 0.53 & 0.96 \\
\hline Nasdaq & $1972-2007$ & -12.80 & 12.41 & 0.79 & 13.53 & 3.39 & 0.57 & 0.97 \\
\hline S\&P 500 & $1972-2007$ & -25.73 & 8.34 & 0.70 & 53.96 & 4.69 & 0.53 & 0.97 \\
\hline
\end{tabular}
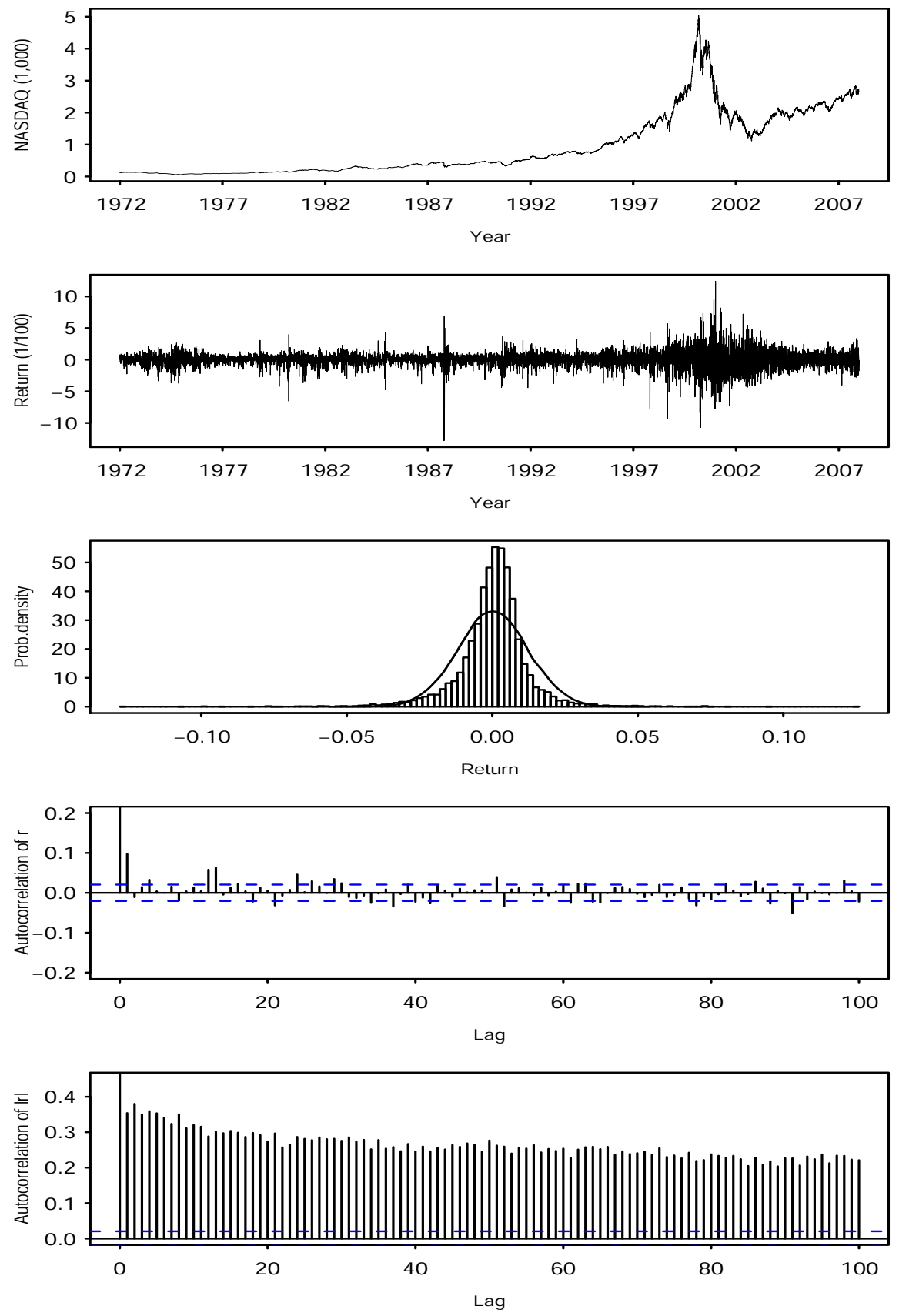

Fig. 1. Time series properties of Nasdaq

distribution with mean $\bar{D}=0.02$ and variance $\sigma_{D}^{2}=0.004$. Therefore, the fundamental price 
Table 2

Parameters for simulations

\section{The stock market}

\begin{tabular}{ll}
\hline Shares of the stock $(h)$ for each trader & 1 \\
\hline Initial money supply for each trader & $\$ 100$ \\
\hline Interest rate $\left(r, r_{d}\right)$ & $(0.05,0.0002)$ \\
\hline Stochastic process $\left(D_{t}\right)$ & $\mathrm{N}\left(\bar{D}, \sigma_{D}^{2}\right)=\mathrm{N}(0.02,0.004)$ \\
\hline Amount for each trade $(\Delta h)$ & 1 \\
\hline Maximum shares of stock holding & 10 \\
\hline Number of rounds for each period $\left(N_{R}\right)$ & 50 \\
\hline Number of periods $\left(N_{P}\right)$ & 20,000 \\
\hline \hline
\end{tabular}

\begin{tabular}{|c|c|}
\hline \multicolumn{2}{|c|}{ Traders } \\
\hline Number of traders $(N)$ & 100 \\
\hline Number of strategies for each trader $\left(N_{I}\right)$ & 20 \\
\hline Tournament size $\left(N_{T}\right)$ & 5 \\
\hline Evolution cycle $\left(N_{E C}\right)$ & 5 \\
\hline$\lambda$ & 0.5 \\
\hline$\theta_{0}$ & 0.5 \\
\hline$\omega$ & 15 \\
\hline$\theta_{1}$ & 0.01 \\
\hline$\theta_{2}$ & 0.001 \\
\hline \multicolumn{2}{|c|}{ Parameters of genetic programming } \\
\hline Function set & $\begin{array}{l}\{\text { if-then-else; and, or , not } ; \geq, \leq,= \\
\quad+,-, \times, \%, \text { sin, cos, abs, sqrt }\}\end{array}$ \\
\hline Terminal set & $\left\{P_{t-1}, \ldots, P_{t-5}, D_{t-1}, \ldots, D_{t-5}\right\}$ \\
\hline Selection scheme & Tournament selection \\
\hline Tournament size & 2 \\
\hline Probability of creating a tree by immigration & 0.1 \\
\hline Probability of creating a tree by crossover & 0.7 \\
\hline Probability of creating a tree by mutation & 0.2 \\
\hline
\end{tabular}

of our model is

$$
P_{f}=\sum_{i=1}^{\infty} \frac{\bar{D}}{R^{i}}=\frac{\bar{D}}{r_{d}}=100 .
$$

Short selling and buying on margin are prohibited. Each trader utilizes the information regarding the stock price and dividend history up to the last 5 periods to form his expectations.

Table 3 summarizes the basic statistical properties for 20 simulations and Fig. 2 display the time series properties of a typical run. In comparison with the results obtained in real financial markets, our model fits these stylized facts very well. The fifth, seventh, and eighth 
Table 3

Statistical properties of the calibrated model

\begin{tabular}{lrrrrrrrrrr}
\hline & $r_{\min }$ & $r_{\max }$ & $|r|$ & $P_{D}$ & $K$ & $V$ & $\sigma_{V}$ & $\alpha$ & $H_{r}$ & $H_{|r|}$ \\
\hline Minimum & -13.85 & 11.80 & 0.31 & 25.21 & 18.57 & 157.18 & 18.50 & 1.91 & 0.47 & 0.90 \\
\hline Median & -20.11 & 17.32 & 0.49 & 43.39 & 49.23 & 168.26 & 21.15 & 3.41 & 0.52 & 0.91 \\
\hline Average & -23.38 & 20.76 & 0.50 & 43.91 & 45.33 & 167.81 & 21.56 & 3.38 & 0.52 & 0.92 \\
\hline Maximum & -45.11 & 32.10 & 0.78 & 66.71 & 81.11 & 173.70 & 26.13 & 4.96 & 0.57 & 0.94 \\
\hline
\end{tabular}

Table 4

Statistical properties of the model with overconfident traders

\begin{tabular}{lrrrrrrrrrr}
\hline & $r_{\min }$ & $r_{\max }$ & $|r|$ & $P_{D}$ & $K$ & $V$ & $\sigma_{V}$ & $\alpha$ & $H_{r}$ & $H_{|r|}$ \\
\hline Minimum & -16.08 & 19.23 & 0.73 & 60.15 & 9.47 & 161.15 & 30.36 & 1.32 & 0.50 & 0.82 \\
\hline Median & -47.30 & 47.24 & 1.90 & 98.43 & 23.54 & 177.11 & 49.73 & 3.68 & 0.56 & 0.95 \\
\hline Average & -57.95 & 963.36 & 5.97 & 97.17 & 209.09 & 179.81 & 47.52 & 3.60 & 0.59 & 0.93 \\
\hline Maximum & -99.81 & 5400.00 & 32.97 & 123.32 & 1128.09 & 222.91 & 55.00 & 7.10 & 0.77 & 0.97 \\
\hline
\end{tabular}

columns of Table 3 are the price distortion $\left(P_{D}\right)$, the trading volume and its standard deviation, respectively. Price distortion which measures the degree of price deviation from the fundamental price is defined as

$$
P_{D}=\frac{100}{N_{P}} \sum_{t=1}^{N_{P}}\left|\frac{P_{t}-P_{f}}{P_{f}}\right|
$$

\section{Simulation results}

Based on the parameters shown in Table 2, we examine the consequences of overconfident traders. Traders' overconfidence is represented by the way that they underestimate their conditional variances. Each trader's overconfidence level is determined by two parameters, $\gamma_{1}$ and $\gamma_{2}$. In this paper, we choose $\gamma_{1}=0.99$ and $\gamma_{2}=1.005$. The results of 20 simulation runs are presented in Table 4, and the time series properties of a typical run is plotted in Fig. 3.

For most of runs, our simulated market with overconfident traders still provides a good fit of the stylized facts. For example, return distribution displays the property of fat-tail. The autocorrelation of raw return series is insignificant and that for the absolute returns is quite significant. Overconfidence makes market exhibit richer dynamics and stronger characteristics. First, price dynamics is more volatile and the scale of bubble and crash is larger. It is no doubt that price distortion would be more serious. In the market without overconfident traders, the median of market volatility is $0.49 \%$. By contrast, it is $1.90 \%$ in the market composed of overconfident traders. Second, comparing the second panel of Figs. 2 and 3, it is clear that overconfidence results in larger return variation. In Table 3, the median of the minimum (maximum) of returns is $-20.11 \%$ (17.32\%) among 20 runs, while it is $-47.30 \%$ $(47.24 \%)$ when traders are overconfident. Overconfidence also causes more significant volatility clustering. This can be evidenced from the higher autocorrelation of absolute returns. Third, from Tables 3 and 4, we observe that trading volume as well as its volatility increase when traders are overconfident. Basically, our findings confirm the analytical results ob- 

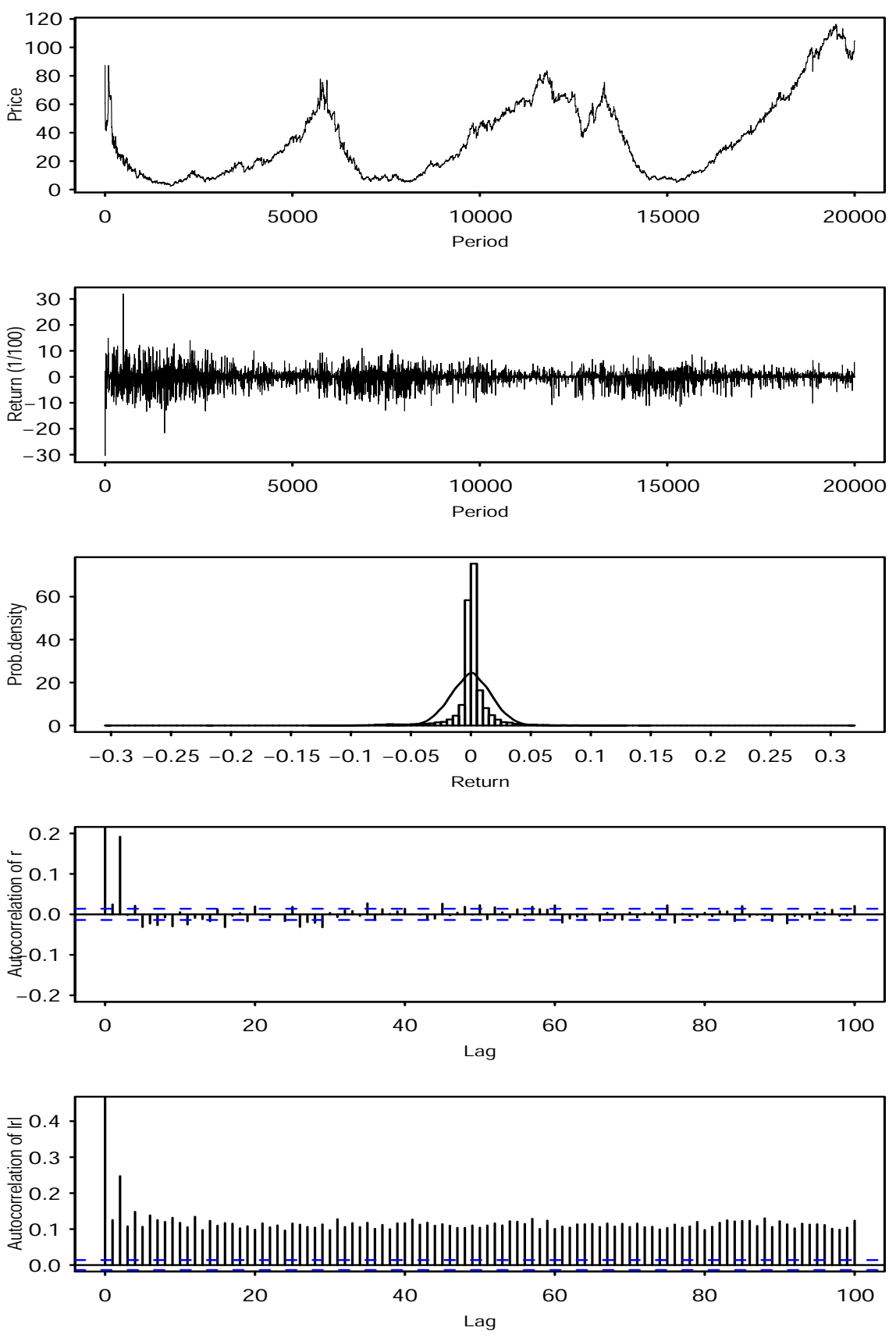

Fig. 2. Time series properties of the calibrated model

tained in Benos (1998) and Odean (1998) where they conclude that overconfidence results in increased price volatility and trading volume.

\section{Conclusion}

How traders' psychological factors affect market properties has been paid much attention in the past decade. Overconfidence is one of most important characteristics. Under an agentbased framework, this paper examines the effects of traders' overconfidence on the market. The preliminary results have shown that overconfidence increases market volatility, price distortion, and trading volume. Some stylized facts such as fat-tail of return distribution and volatility clustering would be more evident. Of course, the results crucially rely on the 

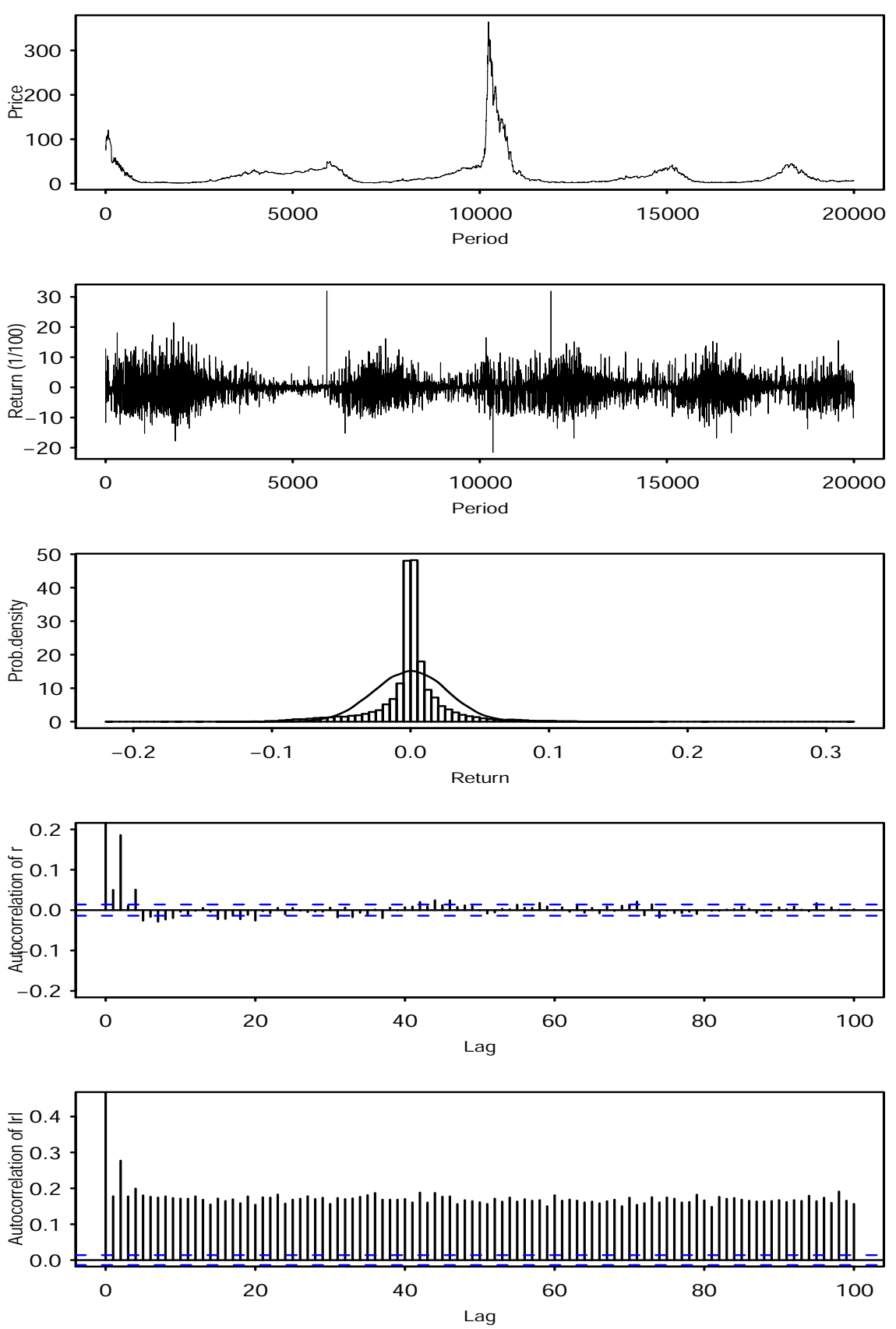

Fig. 3. Time series properties of the model with overconfident traders

design of traders' overconfident behavior. Further investigation regarding this issue would be necessary in the following studies.

\section{Acknowledgement}

Research support from NSC Grant No. 98-2410-H-155-021 is gratefully acknowledged.

\section{References}

Bem, D. J., 1965. An experimental analysis of self-persuasion. Journal of Experimental Social Psychology 1, 199-218. 
Benos, A. V., 1998. Aggressiveness and survival of overconfident traders. Journal of Financial Markets 1, 353-383.

Brock, W., Lakonishok, J., LeBaron, B., 1992. Simple technical trading rules and the stochastic properties of stock returns. The Journal of Finance 47, 1731-1764.

Campbell, J. Y., Shiller, R., 1988. The dividend-price ratio and expectations of future dividends and discount factors. The Review of Financial Studies 1, 195-227.

DeBondt, W. F. M., Thaler, R. H., 1995. Financial decision-making in markets and firms: a behavioral perspective. In: Jarrow, R. A., Maksimovic, V., Ziemba, W. T. (Eds), Finance, Handbooks in Operations Research and Management Science 9, 385-410. North Holland, Amsterdam.

De Long, J. B., Shleifer, A., Summers, L. H., Waldmann, R. J., 1989. The size and incidence of the losses from noise trading. The Journal of Finance 44, 681-696.

De Long, J. B., Shleifer, A., Summers, L. H., Waldmann, R. J., 1990a. Positive feedback investment strategies and destabilizing rational speculation. The Journal of Finance 45, 379-395.

De Long, J. B., Shleifer, A., Summers, L. H., Waldmann, R. J., 1990b. Noise trader risk in financial markets. The Journal of Political Economy 98, 703-738.

De Long, J. B., Shleifer, A., Summers, L. H., Waldmann, R. J., 1991. The survival of noise traders in financial markets. The Journal of Business 64, 1-19.

Friedman, M., 1953. The case for flexible exchange rates. In: Essays in Positive Economics. University of Chicago Press, Chicago, IL.

He, X.-Z., Li, Y., 2007. Power-law behaviour, heterogeneity, and trend chasing. Journal of Economic Dynamics and Control 31, 3396-3426.

Hirshleifer, J., 2001. Investor psychology and asset pricing. The Journal of Finance 56, 15331597.

Kogan, L., Ross, S. A., Wang, J., Westerfield, M. M., 2006. The price impact and survival of irrational traders. The Journal of Finance 61, 195-229.

Lo, A. W., MacKinlay, A. C., 1988. Stock prices do not follow random walks: evidence from a simple specification test. The Review of Financial Studies 1, 41-66.

Neely, C., Weller, P., Dittmar, R., 1997. Is technical analysis in the foreign exchange market profitable? a genetic programming approach. Journal of Financial and Quantitative Analysis 32, 405-426.

Odean, T., 1998. Volume, volatility, price, and profit when all traders are above average. The Journal of Finance 53, 1887-1934.

Shleifer, A., Summers, L. H., 1990. The noise trader approach to finance. The Journal of Finance 4, 19-33.

Simon, H. A., 1957. Models of Man. Wiley, New York, NY.

Tversky, A., Kahneman, D., 1974. Judgement under uncertainty: heuristics and biases. Science 185, 1124-1131.

Yeh, C.-H., 2007. The effects of intelligence on price discovery and market efficiency. Computational Economics 30, 95-123.

Yeh, C.-H., 2008. The role of intelligence in time series properties. Journal of Economic Behavior and Organization 68, 613-625. 